\title{
Pharmaceutical Care in Tbilisi Pharmacies
}

\author{
N. Nemsitsveridze*, N. Gorgaslidze, T. Chumburidze, N. Dughashvili, T. Zarkua, S. Voronovi \\ Department of Social and Clinical Pharmacy, Tbilisi State Medical University, Georgia
}

Copyright $(2016$ by authors, all rights reserved. Authors agree that this article remains permanently open access under the terms of the Creative Commons Attribution License 4.0 International License

\begin{abstract}
Pharmaceutical care represents the patient-oriented future profession that is focused on identification, eradication and prevention of the problems connected to the drug treatment. The aim of the study was to detect the role of pharmacist in treatment. Thus it was necessary to find out doctors and pharmacists opinion about this topic. The method of the study was anonymous survey, of pharmacists and doctors. "Pharmaceutical care" in Tbilisi pharmacies was evaluated. We performed the analysis of the statistical data from the anonymous questionnaires delivered to 30 pharmacists and 30 physicians. Concerning the character of the request, frequently it is connected to the drug selection which is issued without any prescription, according to the $95 \%$ ( $45 \%$ often $+50 \%$ rarely) of the respondents, majority of the patients request the original medicine to be changed with the generic one, which is according to their opinion determined by the high price of the original medicine. On the question about how many patients are advised, 54\% of the pharmacists responded that every day from 50-70 patients address them to select drug or give consultation concerning the drug treatment. On the question about how frequently are patients redirected to the doctors, according to the questioning that consists of $50 \%$, which means that half of the patients' needs consultation of the doctors and pharmacist warn them concerning this issue. For the reason to find the dependence of the doctors on pharmacist's care we made internet survey. $65 \%$ of doctors believe that patient care belongs exclusively to the physician and only $35 \%$ of responders agreed to share this function with the pharmacist. In conclusion for avoiding misunderstanding between physicians and pharmacists and also for solving other problems detected during this study it is necessary to upgrade the qualification of pharmacists in clinical issues.
\end{abstract}

Keywords Pharmacy Practice, Pharmaceutical Care, Health Care System

\section{Introduction}

The recent years' concept of patient-oriented health care system considers the development of pharmaceutical services and their implementation into the system along with the optimization of financial expenses, reduction of drug side effects, and enhanced quality of life for both patient and the entire society. Pharmaceutical care represents the patient-oriented future profession that is focused on identification, eradication and prevention of the problems connected to the drug treatment. In the developed countries approximately $10 \%$ of the patients have side effects developed due to drug usage, especially if we deal with the aged patients and patients having chronic disease with multi-drug treatment. $(1,2)$

Correspondingly, the pharmacists' responsibility for patients increases. The notion "pharmaceutical care" suggests the qualified assistance for the patient, that is associated not only with advisory functions, when a selection of nonprescription drug is needed, but also consulting patient about dosage regimens, possible interactions with other drugs and food, as well as redirecting to the physician, if necessary. $(3,4)$

When assisting a patient, the pharmacist should take into account all the factors about both the patient and possible side effects of the drug for the minimization of further treatment-related problems. At present, pharmacists are trained to obtain appropriate skills required for giving individual patient-specific drug recommendations, consulting about effective and safe drug usage, and warning about self-treatment risks.(5)

\section{Aim \\ The aim of the study was to detect the role of pharmacist in treatment. Thus it was necessary to find out doctors and pharmacists opinion about this topic.}

\section{Materials and Methods}

The method of the study was anonymous survey, of pharmacists and doctors. The data was statistically analysed using Epilnfo method.

It was evaluated the "pharmaceutical care in Tbilisi pharmacies, what kind of problems pharmacists are faced to when communicating with patients and physicians, how can 
the pharmacist fit a leading role in patient-oriented and sustainable public health activities. We performed the analysis of the statistical data from the anonymous questionnaires delivered to 30 pharmacists and 30 physicians.

\section{Questionnairy for pharmasicts:}

1. Do the patients refer to you for advices?

2. What kind of advices do they need more frequently?

3. How often do they ask you to change original drugs with generics?

4. How often do you send patients to doctors?

The results of survey are shown on diagrams

\section{Results}

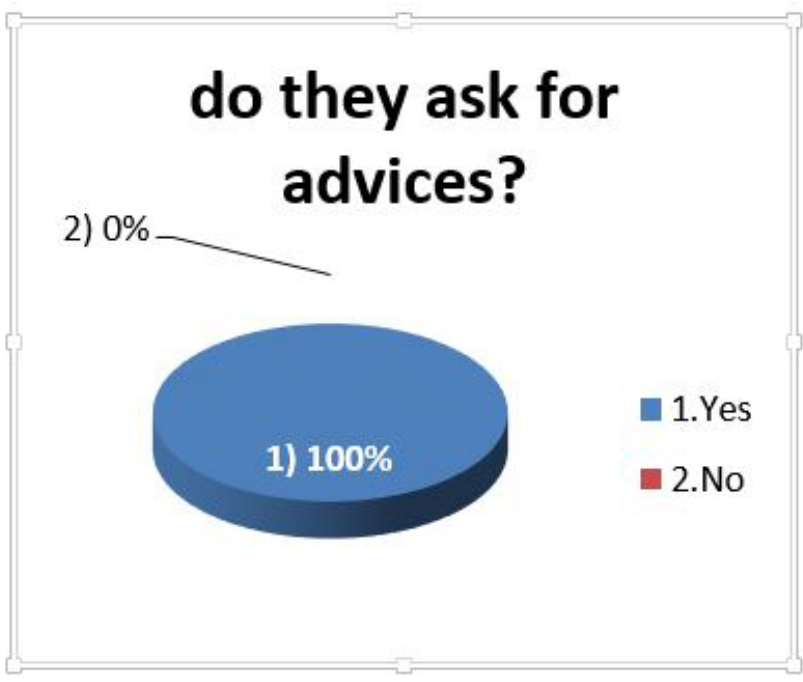

Figure 1.

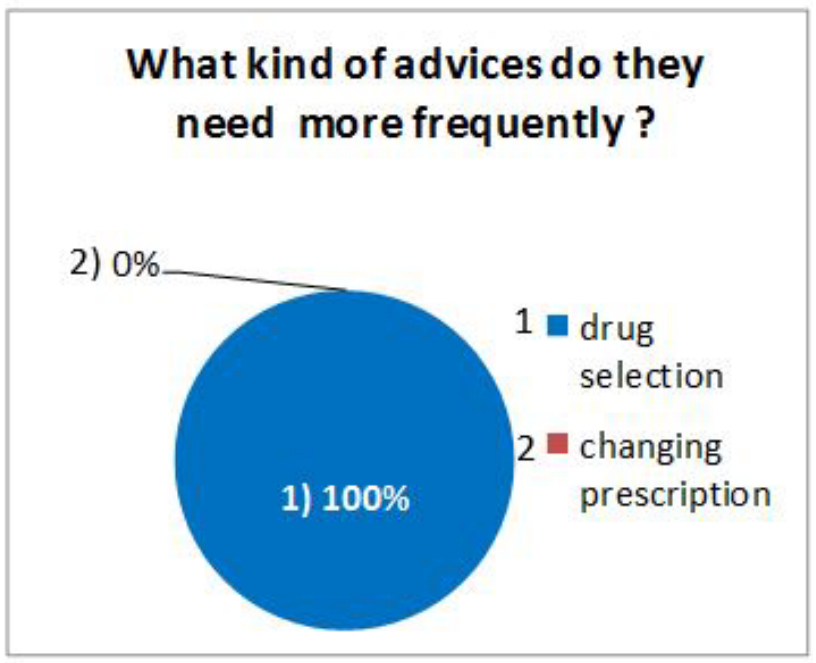

Figure 2.

As is seen in the Fig.1., the $100 \%$ of the respondents certify that they give every day advice concerning the medicine. Concerning the character of the request, frequently it is connected to the drug selection which is issued without any prescription (Fig.2.).

The figure 3 shows that majority of the patients- $95 \%$ respondents [ $45 \%$ often $+50 \%$ rarely] from which $45 \%$ [95\% $\mathrm{CI}=26,6-63,6]$ and $50 \%[95 \% \mathrm{CI}=31,6-68,4]$ request the original medicine to be changed with the generic one, which is according to their opinion determined by the high price of the original medicine.

On the question that is connected to how many patients are adviced, $54 \%(95 \% \mathrm{CI}=43,6-64,4)$ of the pharmacists responded that every day from 50-70 patients address them to select drug or give consultation concerning the drug treatment. (Fig.4)

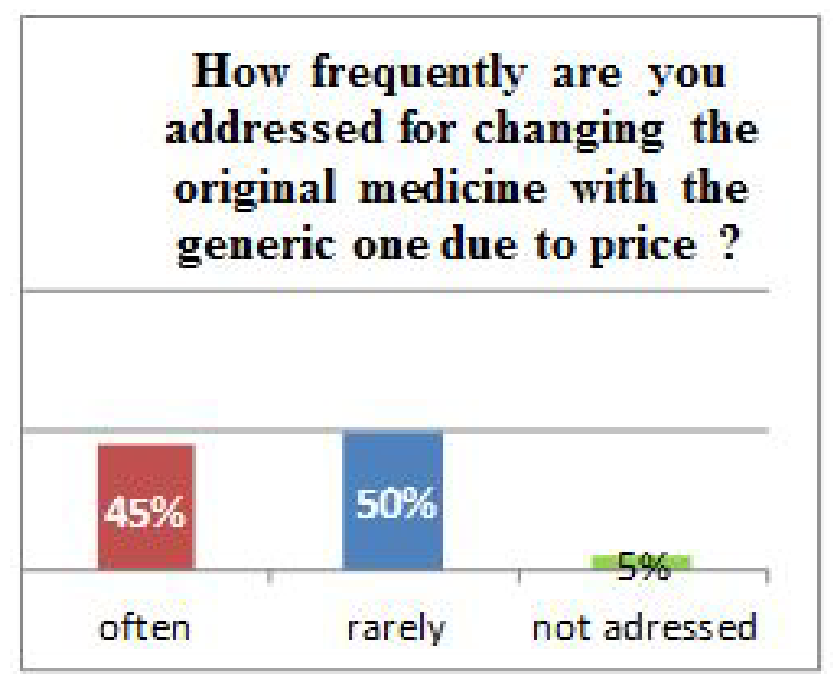

Figure 3

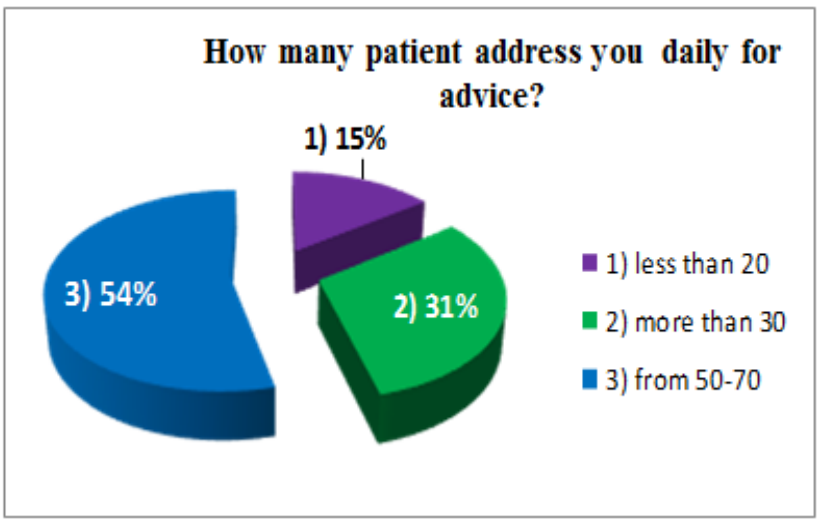

Figure 4.

Doctors and pharmacists relationship is very painful. According to the doctors view, pharmacists with their care intrude into the doctor's function which is not true, the pharmacist represents the intermediate line between the doctor and the patient, they work only in the frames of their competence, that is connected only with the drug selection issued without any prescription and if the patient's symptoms are serious they are send to doctors.

On the question about how frequently are patients redirected to the doctors, according to the questioning that 
consists of $50 \%$, which means that half of the patients need consultation of the doctors and pharmacist warn them concerning this issue (Fig.5).

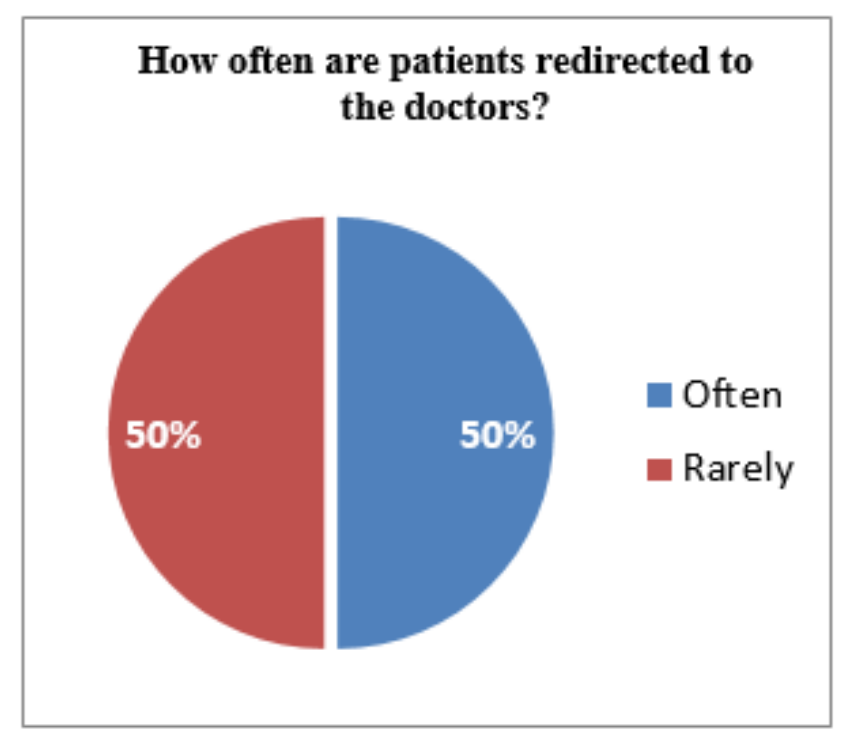

Figure 5

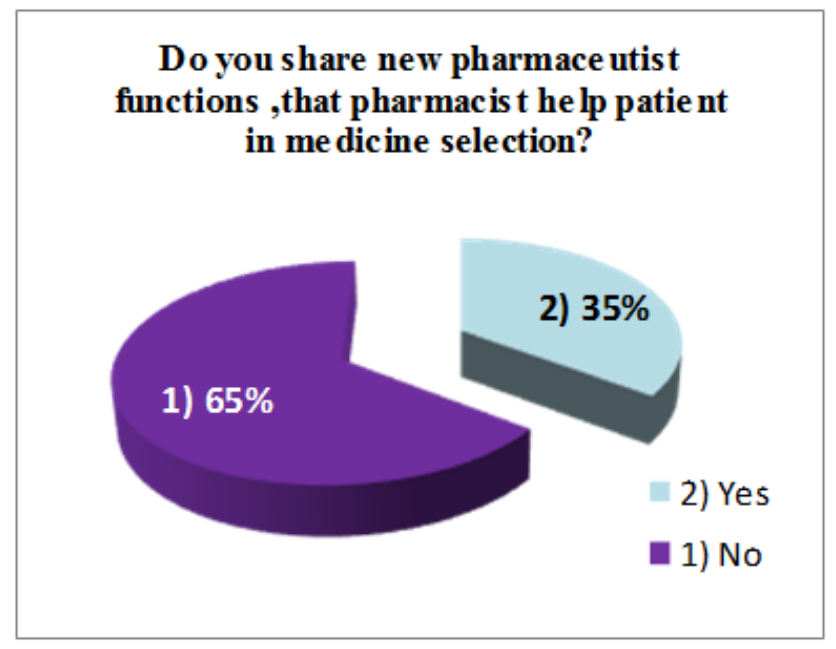

Figure 6.

For the reason to find the dependence of the doctors on pharmacist's care we made internet questioning, 30 doctors responded the question, how do the doctors share new pharmacists function, that in some case pharmacist advice the patient concerning the medicine that is issued without the prescription, which does not skip its competence frames, they do not intervene into the doctors' prescription, foresees the drugs interaction, pharmacokinetic and biopharmaceutics factors.

At the same time when doctors were asked to estimate a pharmacist's additional roles, particularly the consultations on selection of nonprescription drugs, $65 \% \quad(95 \%$
$\mathrm{CI}=47,3-82,7)$ of doctors believe that this function belongs exclusively to the physician and only $35 \%(95 \%$ $\mathrm{CI}=17,4-52,6)$ of responders agreed to share this function with the pharmacist.

\section{Conclusions}

Based on the obtained results, we can conclude that despite some resistance, the pharmacists in Tbilisi hold quite favorable position to ensure the effective and safe use of medicines, but they have to take more responsibility for the drug therapy management, so they can fulfill the effective role in the health group, implement new clinical skills and become deserving person of the 7 star pharmaceutic conception developed by the International Pharmaceutical Federation and World Health Organization. $(6,7)$

Moreover, for avoiding misunderstanding between physicians and pharmacists and also for solving other problems detected during this study it is necessary to upgrade the qualification of pharmacists in clinical issues.

\section{REFERENCES}

[1] T.Tchumburidze, T.Kikaleishvili, Clinical Pharmacy. Tbilisi 2006

[2] Georgian Law on Drugs and Pharmaceutical activities, Georgia 2009

[3] American College of Clinical Pharmacy, The Definition of Clinical Pharmacy, (Washington 2008)

[4] FIP "Statement Of Professional Standards Pharmaceutical Care”, Hague, The Netherlands, 1998.

[5] Luc Besancon, Pharmaceutical care-Summary Of A Survey, 2009

[6] FIP "Statement Of Professional Standards Pharmaceutical Care”, Hague, The Netherlands, 1998.

[7] FIP, Reference Paper, Collaborative Practice, Istanbul, Turkey 2009

[8] Westerlund LT, Bjork HT. Pharmaceutical care in community pharmacies: practice and research in Sweden. Ann Pharmacother. 2006;

[9] Noyce PR. Providing patient care through community pharmacies in the UK: policy, practice, and research. Ann Pharmacother. 2007;

[10] Eickhoff C, Schulz M. Pharmaceutical care in community pharmacies: practice and research in Germany. Ann Pharmacother. 2006. 